\title{
Lorenzo Mainini, Gli anni della tradizione: testi, codici e culture (secc. XII eX.- XIV in.). Capitoli per una storia materiale
}

\section{Piero Andrea Martina}

\section{OpenEdition}

\section{Edizione digitale}

URL: https://journals.openedition.org/studifrancesi/20656

DOI: 10.4000/studifrancesi.20656

ISSN: 2421-5856

\section{Editore}

Rosenberg \& Sellier

\section{Edizione cartacea}

Data di pubblicazione: 1 décembre 2019

Paginazione: $544-545$

ISSN: 0039-2944

\section{Notizia bibliografica digitale}

Piero Andrea Martina, «Lorenzo Mainini, Gli anni della tradizione: testi, codici e culture (secc. XII ex.- xIV in.). Capitoli per una storia materiale», Studi Francesi [Online], 189 (LXIII | III) | 2019, online dal 01 mars 2020, consultato il 11 novembre 2021. URL: http://journals.openedition.org/studifrancesi/20656 ; DOI: https://doi.org/10.4000/studifrancesi.20656

Questo documento è stato generato automaticamente il 11 novembre 2021.

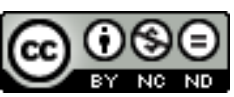

Studi Francesi è distribuita con Licenza Creative Commons Attribuzione - Non commerciale - Non opere derivate 4.0 Internazionale. 


\title{
Lorenzo Mainini, Gli anni della tradizione: testi, codici e culture (secc. XII eX.- XIV in.). Capitoli per una storia materiale
}

\author{
Piero Andrea Martina
}

\section{NOTIZIA}

Lorenzo Mainini, Gli anni della tradizione: testi, codici e culture (secc. XII ex.- XIV in.). Capitoli per una storia materiale, Roma, Società Filologica Romana - Viella, 2017, «Biblioteca di Studj Romanzi» 2, 356 pp.

1 Ambizioso: tale è il libro di L.M., a volerlo definire in una parola. Come appare chiaro dal titolo e dalla ricca introduzione dal taglio metodologico, L.M. intende fornire uno studio della produzione e circolazione dei testi medievali, in una prospettiva che è tanto migliore quanto poco adottata: lo sguardo alla produzione $e$ latina $e$ romanza. I limiti temporali di questo studio sono definiti con chiarezza - tra la fine del xII e l'inizio del XIV sec.-, cioè quel XIII sec. allargato, che è centrale per l'affermazione del libro volgare (cf. p.15). Le aree d'indagine sono quelle italoromanze e galloromanze, in special maniera, e certo è proprio la scelta delle aree geografiche ad aver influito sulla scelta dell'arco temporale. Ciò che conta per L.M. è studiare i testi composti e letti all'interno di quello che viene identificato, geograficamente e storicamente, come uno spazio significativo dell'Occidente latino.

2 L'Autore utilizza, per fare ciò, diverse metodologie d'indagine: dallo studio minuto delle circostanze di copia di un testimone al percorso di una tradizione testuale, dall'analisi dei cataloghi e inventari di biblioteche antiche alla biblioteca 'allusa' di un autore, fino ad arrivare a un passo da metodi più quantitativi, pure evitati (p. 19, dove si sarebbero potuti evocare i lavori di E. Ornato e C. Bozzolo). 
3 L'indagine si fonda dunque su una massa di dati (circa $2000 \mathrm{mss}$ ) il cui spoglio ha richiesto ben più del tempo del dottorato di ricerca, della cui tesi questo libro è la finale rielaborazione. Poiché tale massa di dati è non sempre citata direttamente, il lettore non può che attendere con ansia la pubblicazione di un catalogo, anche sommario, anche parziale, della documentazione che L.M. ha spogliato. Se, per ora, ci si deve contentare dell'indice dei manoscritti citati, un complemento, anche se limitato, può ritrovarsi nel catalogo della mostra I libri che hanno fatto l'Europa. Manoscritti latini $e$ romanzi da Carlo Magno all'invenzione della stampa (a cura di R. Antonelli et al., Roma, Accademia Nazionale dei Lincei, 2016, cui L.M. ha collaborato) -, catalogo analitico di materiali che Gli anni della tradizione provano a sintetizzare.

L.M. ci obbliga a un vero tour de force intellettuale, spostandosi come fa da un piano generale a uno particolare, alternando diverse scale per disegnare la sua carta geografica della cultura scritta del XIII sec. (abbondante). Se il dato materiale è importante, non è questo il centro del discorso dell'Autore. Egli vuole infatti conoscere «la 'biblioteca', le letture e la memoria testuale» (p. 11) dei secoli che considera. «Rispetto ad altri studi sulla tradizione materiale, in queste pagine la circolazione del testo, nelle sue forme libro, è concepita, tendenzialmente, come un aspetto dell'intertestualità e dell'interdiscorsività producibili in un comune spazio di cultura; ma vale ugualmente la proposizione inversa: che un comune spazio di cultura risulti dall'intertestualità e dall'interdiscorsività generate da affini circolazioni librarie» (p. 12). Si scopre un discorso critico che si potrebbe definire marxista laico, o neo-marxista (se interpreto bene): si sottolineano delle condizioni pragmatiche che sono alla base di una cultura e che bisogna rintracciare se si vuole cercare di comprendere quest'ultima. In ogni caso, quest'idea dell'“immanenza libraria" del dato letterario (generi? canoni? «saperi»?) è uno degli aspetti più interessanti degli Anni della tradizione.

5 Lo sguardo di L.M. si sviluppa così all'indietro - la memoria che un testo conserva, ma anche il milieu (intellettuale, ma pure fisico) in cui viene scritto - ma pure in avanti - la 'vita' di un testo e il milieu (c.s.) in cui lo si ritrova.

6 Il volume si articola in sei capitoli: 1. Letture dei classici; 2. Il libro storiografico; 3. Forme del testo giuridico; 4. Oltre la distinzione di trivio e quadrivio; 5. Circolazione del discorso teologico (è il sottotitolo); 6. Il 'libro letterario' in volgare. Il che dà l'idea dell'ampiezza di sguardo, che è la forza del libro, al di là delle singole piccole mende di dettaglio, che non ne inficiano la portata. I capitoli non sono quelli di una storia letteraria latino-italofrancese del XIII sec., e come tali non devono essere letti, quanto piuttosto come un tentativo di rintracciare, nei diversi generi letterari presi in esame, le differenze di cultura.

7 Con un campo di studio così vasto, è normale che nella redazione finale siano scivolati alcuni errori e difformità (ad es., sui criteri di trascrizione), alcune bizzarrie (ad es. la modalità di trascrizione delle glosse; l'ordine dei titoli in bibliografia) così come alcune formulazioni ripetitive (come quella in apertura del paragrafo 6.3, p. 257, che ridefinisce una «linea interpretativa» che è quella dell'intero libro, mi pare): non sarà questa la sede per evidenziare coquilles, che l'Autore avrà la premura di correggere nella seconda edizione.

Da un punto di vista più generale, che renda grazie del lavoro di L.M., mi sembra che il libro inviti alla discussione su almeno tre punti: innanzitutto la nozione e l'opportunità 
del 'canone' nelle diverse branche della cultura scritta qui analizzate (che cos'è 'classico' per un autore del xiII sec., per esempio? cf. cap. 1).

9 In secondo luogo, la 'proporzionalità' (anche solo dal punto di vista numerico) tra libro latino e libro volgare, che l'Autore non prende se non marginalmente in conto. Se il confronto tra la cultura scritta volgare con quella latina è necessario, indispensabile, tuttavia non bisogna nascondere che L.M. adotta la prospettiva del filologo romanzo (cioè quella di comparare), e dunque porta il suo sguardo principalmente sul dato volgare, com'è normale e giusto che sia: il quale risulterebbe annegato dal dato latino, se si rispettassero le proporzioni tra le due produzioni, nei quindici decenni $c a$ in questione.

10 Infine, pare di notare in L.M. una volontà come di giustificare il proprio lavoro di studio della storia dei testi, che egli sottolinea, in quanto "storia della tradizione" - e dunque legata alla critica del testo, almeno fin da Pasquali -, far parte del lavoro filologico. Leggere, trascrivere, comparare, catalogare, comprendere sono azioni del filologo; farlo con uno sguardo aperto a differenti tradizioni è ciò cui L.M. ci invita. 